\title{
패션기업 $\mathrm{CEO}$ 의 진정성 리더십이 직원의 직무만족 및 조직성과에 미치는 영향
}

\author{
박 동 진 ${ }^{+} \cdot$ 이 혜 주 \\ 중앙대학교 패션디자인학과 박사과정 ${ }^{+}$중앙대학교 패션디자인학과 명예교수
}

\section{Effects of the CEO's Authentic Leadership of Fashion Company on Job Satisfaction and Organizational Performance}

\author{
Dongjin Park ${ }^{+} \cdot$ Hyejoo Lee \\ Ph.D. Student, Dept. of Fashion \& Design, Chung Ang University ${ }^{+}$ \\ Emeritus Professor, Dept. of Fashion \& Design, Chung Ang University \\ (received date: 2016. 10. 4, revised date: 2016. 11. 22, accepted date: 2016. 11. 27)
}

\begin{abstract}
This study analyzed the effects of CEO's authentic leadership on job satisfaction and organizational performance in a fashion company, and the differences in the CEO's authentic leadership, job satisfaction and organizational performance by the size of the companies. The study analyzed responses collected from questionnaires filled out by 440 employees of fashion companies. The results of this study were as follows; First, the transparency, future orientation, self-awareness, balanced process, and ethicality of CEO's authentic leadership positively influenced the wages or system satisfaction. The CEO's transparency, future orientation, self-awareness, and ethicality positively influenced job satisfaction. Also, the CEO's transparency, future orientation, self-awareness positively influenced the working condition or environmental satisfaction. Second, the wages or system satisfaction and working condition or environmental satisfaction of employees positively influenced the management performance of fashion companies. And the wages or system satisfaction, job satisfaction and working condition or environmental satisfaction of employees positively influenced the new product performance and job performance. Third, the CEO's authentic leadership of fashion companies positively influenced the management performance, and the CEO's transparency and future orientation positively influenced the new product performance. In addition, the CEO's self-awareness, balanced process and ethicality influenced the job performance. Fourth, there were significant differences in the CEO's authentic leadership, job satisfaction, management performance and new product performance by fashion companies' size. The results of this study will be useful in successful business strategy and improving the performance of fashion companies.
\end{abstract}

Key words: authentic leadership(진정성 리더십), fashion company(패션기업), job satisfaction(직무만족), organizational performance(조직성과)

이 논문은 박사학위 청구논문의 일부임

Corresponding author: Dong Jin Park e-mail: skla@nate.com 


\section{I . 서론}

트렌디하면서도 새로운 디자인으로 유행을 선 도하는 패션기업에서는 $\mathrm{CEO}$ 의 기업가 정신이나 가치관, 리더십 등이 직원들의 의사결정을 원활히 하거나 성과를 향상시키는 중요한 요소가 되고 있 다(Hong, 2010). 다시 말해, $\mathrm{CEO}$ 가 조직의 궁극 적 방향성 제시하고, 동기부여를 통해 구성원들이 지속적인 성과를 창출할 수 있도록 조직을 이끌어 나가는 핵심이라고 할 수 있다. 그러나 국내 패션 기업의 대부분이 영세한 자본구조로 운영되고 있 는 중소기업으로서 조직적인 경영관리가 이루어지 지 않을 뿐 아니라 급여체계의 불공정, 인사 및 조직관리의 미흡, 경영층의 비전제시 및 리더십 부재와 같은 악조건 속에서 시간이 지날수록 경쟁 력을 상실하고 있다. 이러한 시점에 패션기업의 성과를 향상시키고 경쟁력을 회복하기 위한 방안 으로서 $\mathrm{CEO}$ 의 리더십이 요구되고 있으며, 최근 들어 기업의 사회적 책임과 지속가능한 발전이 중 요해지면서 $\mathrm{CEO}$ 의 진정성 리더십이 주목을 받고 있다.

진정성 리더십은 '자기인식, 내면화된 도덕적 관 점, 균형 잡힌 정보처리와 관계적 투명성을 육성하 기 위한 긍정적인 심리적 능력과 윤리적 환경을 촉진하는 리더의 행동 유형(Walumbwa, Avolio, Gardner, Wernsing, \& Peterson, 2008)'으로서, 리더 의 행동이 개인의 가치관, 신념과 일관성이 있을 때 진정성이 있는 것으로 간주된다(Avolio, Gardner, Walumbwa, Luthans, \& May, 2004). 진정성 리 더십은 '명확한 자기 인식을 바탕으로 확고한 가 치와 원칙을 세우고 투명한 관계를 기반으로 내적 인 자아(private self)와 외적인 자아(public self) 사이의 격차를 최소화함으로써 조직구성원들에게 긍정적인 영향력을 행사하는 능력(Ryu, 2016)'을 말하며, 조직 구성원들의 긍정적인 태도와 행동을 촉진하여 조직의 성과에 기여하는 중요한 리더십 이라 할 수 있다(Rego, Sousa, Marques, \& Cunha,
2012).

지금까지 진정성 리더십에 관한 경험적 연구 (Agote, Aramburu, \& Lines, 2016; Cha, Jung, \& Kim, 2015; Kim \& Hong, 2015; Koo \& Lee, 2014; Seo, 2015)들은 진정성 리더십이 조직 구성 원의 직무만족과 몰입, 조직성과 및 유효성에 미 치는 영향력을 분석하여 왔고, 리더의 진정성 리 더십이 직무만족을 통해 조직성과를 높이는 것으 로 밝혀지고 있어(Davish \& Rezaei, 2011) 패션 기업 $\mathrm{CEO}$ 의 진정성 리더십이 직원들의 직무만족 과 조직성과를 높일 것으로 예측할 수 있다. 하지 만, 선행연구들은 호텔이나 스포츠센터 등의 특정 서비스 업종 $\mathrm{CEO}$ 와 중소기업 및 인적 자원 관리 자 등을 대상으로 연구가 이루어져 왔고 패션기업 을 대상으로 분석한 연구는 전무한 실정이다. 유 행에 민감한 패션산업의 특성상 타 산업의 연구결 과를 그대로 적용하기에는 어려움이 있으므로 패 션기업 $\mathrm{CEO}$ 의 진정성 리더십과 직원들의 직무만 족 및 성과에 대한 연구가 요구된다. 또한 패션분 야의 관련 연구에서는 패션기업 $\mathrm{CEO}$ 와 팀장의 변혁적 리더십과 직무만족을 분석 (Choi \& Lee, 2009; Hong, 2010)하거나 패션디자이너의 직무만 족에 영향을 미치는 조직유형을 밝힌 연구(Shin \& Soh, 2015), 패션기업 $\mathrm{CEO}$ 의 감성적 리더십과 기업성과에 대한 연구(Kim \& Yang, 2015) 등이 진행되고 있으나 $\mathrm{CEO}$ 의 진정성 리더십에 관한 분석은 이루어지지 않고 있어 이에 관한 연구가 필요하다.

따라서 본 연구는 패션기업 $\mathrm{CEO}$ 의 진정성 리 더십을 규명하고, 진정성 리더십이 직원의 직무만 족과 조직성과에 미치는 영향을 분석하여 조직과 개인의 성과를 높이는데 있어 진정성 리더십의 중 요성을 확인하는데 그 목적이 있다. 뿐만 아니라 기업 규모에 따라서 리더십에 대한 인식과 직무만 족 및 성과가 달라지는 것으로 나타나고 있으므로 (I. S. Kim, 2015; Kim, 2012), 패션기업의 규모에 따라 $\mathrm{CEO}$ 의 진정성 리더십과 직무만족 및 조직 
성과에 어떠한 차이가 있는지를 분석하고자 한다. 본 연구의 결과는 패션기업 $\mathrm{CEO}$ 가 리더십을 발 휘하는 과정에서 진정성 리더십의 중요성을 확인 하고, 직원들의 만족도와 성과를 높일 수 있는 진 정성 리더십 요인을 밝힘으로써 패션기업의 경영 전략에 도움이 되는 자료를 제공할 수 있다.

\section{II. 이론적 배경}

\section{1. 진정성 리더십}

진정성 리더십은 리더십 개발 과정의 개념적 이 론으로서(Avolio \& Gardner, 2005), 긍정 심리학, 긍정 조직 행태, 변혁적 리더십, 윤리적 리더십, 서 번트 리더십 등과 같은 이론적 논의들을 통합하는 과정을 통하여 발전하였다(Peus, Wesche, Streicher, Braun, \& Frey, 2012). 진정성 리더십은 모든 리더십의 근간이 되는 개념으로 긍정적 형태 의 리더십이며(Avolio, Luthans, \& Walumbwa, 2004), Illies, Morgeson, \& Nahrgang(2005)은 자 아 인식, 균형적 정보처리, 진정성 있는 행동, 진 정한 관계 지향의 리더십을 의미한다고 하였다. Walumbwa et al.(2008)은 진정성 리더십을 자기 인식, 내재화된 도덕적 관점, 정보의 균형적인 프로 세스 및 관계적 투명성을 보다 발전시키기 위하여 긍정 심리 역량과 분위기를 만들어 내며 증진시키 는 리더의 행동양식으로 정의했다. Harter(2002)에 의하면 진정성 리더십은 개인의 경험과 가치, 감 정, 욕망, 선호, 신념 및 진정한 자아의식에 따라 행동하는 것을 말하며, 진정성을 지닌 사람은 조 직 내에서 보다 투명하고 공개적임으로써 긍정적 인 결과를 이끌어낼 수 있다(George, Sims, McLean, \& Mayer, 2007). 이러한 진정성 리더십은 개념적 연구가 주를 이루었고 실증적 연구는 기초 단계에 불과하지만, Walumbwa et al.(2008)에 의 해 진정성 리더십의 측정척도가 개발되어 그 타당 성을 인정받으면서 다양한 분야에서 연구가 진행 되고 있다.
Kernis(2003)는 진정성 리더십을 자아 인식, 비 편향적 정보처리와 의사결정, 관계의 투명성 및 진실한 행동으로 구성된 개념이라 하였고, Avolio \& Gardner (2005)는 긍정적 심리자산, 긍정적 도 덕성, 자아인식과 자아규제 리더십 과정 등을 진 정성 리더십의 구성요소로 제시하였다. Gardner, Avolio, \& Walumbwa(2005)은 진정성 리더십을 자아 인식, 내재화된 규제, 균형적인 정보처리, 관 계적 투명성, 진정성 있는 행동으로 분류하였으며, Illies et al.(2005)은 자아인식, 편견 없는 프로세 스, 진정성 있는 행동과 관계 지향의 네 가지 요 인으로 구분하였다. 또한 Walumbwa et al.(2008) 은 진정성 리더십의 구성 개념으로 자아 인식, 관 계적 투명성, 균형적 정보처리, 내면화된 도덕 관 점을 제시하였다. 이들 선행연구에서는 진정성 리 더십을 자아 인식, 관계적 투명성, 균형적 정보처 리로서의 공정성, 긍정적 도덕성 및 윤리성 등으 로 구성된 개념으로 보고 있으며, May, Chan, Hodges, \& Avolio(2003)에 의하면 진정성 리더가 희망적, 긍정적, 도덕적, 윤리적이며 미래 지향적 특성을 갖고 있으므로 미래지향성도 진정성 리더 십의 구성요소라 할 수 있다.

진정성 리더십은 직무만족(Koo \& Lee, 2014; $\mathrm{Seo}, 2015)$, 조직성과 및 조직유효성(Clapp-Smith, Vogelgesang, \& Avey, 2009; J. B. Kim, 2015; Kim \& Hong, 2015), 조직시민행동(Kim, Moon, \& Park, 2013; Walumbwa, Wang, Wang, Schaubroeck, \& Avolio, 2010), 조직몰입 및 신뢰 (Agote et al., 2016; Cha et al., 2015) 등에 영향을 미치 는 것으로 확인되어 왔다. Clapp-Smith et al. (2009)은 진정성 리더십이 기업의 재무적 성과와 개방적인 풍토에 영향을 미친다고 하였고, Agote et al.(2016)은 진정성 리더십이 직원들의 리더 신 뢰, 긍정적인 감정에 영향을 미친다고 하였다. $\mathrm{Seo}$ (2015)의 연구에서는 진정성 리더십이 직무만 족에 영향을 미치는 것으로 나타났으며, Koo \& $\mathrm{Lee}$ (2014)는 진정성 리더십의 자아인식, 내면화된 
도덕관점, 균형적 정보처리가 직무만족에 정 $(+)$ 의 영향을 미친다고 하였다. 이 외의 연구(J. B. Kim, 2015; Kim \& Hong, 2015)에서도 $\mathrm{CEO}$ 의 진정성 리더십이 직무만족과 혁신행동, 조직몰입 및 신뢰, 조직성과 등에 영향을 미치는 것으로 밝혀졌으므 로 패션기업 $\mathrm{CEO}$ 의 진정성 리더십은 직원들의 직무만족과 조직성과를 높이는 리더십이라 할 수 있다.

\section{2. 직무만족}

직무만족은 조직의 효과성을 알 수 있는 중요 한 요인으로서 '직무수행의 과정에서 조직 구성원 들의 욕구가 충족되어 직무에 대한 관심이나 애 착, 열의를 나타내는 긍정적인 직무 태도 $\left(\mathrm{Ne}^{-}\right.$ termeyer \& Maxham, 2007)'를 의미하며, 직무뿐 만 아니라 직무와 관련된 인간관계, 개인의 감정 적 느낌과 태도, 임금 및 근무시간과 같은 근로조 건 등에 대한 정서적 반응을 나타낸다(Lee, Yoo, \& Kim, 2014). Price(2004)는 직무만족에 대하여 조직의 구성원이 조직에 참여하면서 가지는 긍정 적 감정의 지향이라고 하였으며, Antoncic \& Antoncic(2011)은 직무 만족이란 직원들이 일을 좋 아하는 정도로서 근무시간이나 근무조건, 동료관 계, 급여, 승진 등과 같은 요인들에 의해 인지적으 로 작용한다고 하였다. Doughty, May., Butell, \& Tong(2002)은 직무만족이 직무참여, 동료 간 화 합, 상사의 지지와 자율적인 행동기회 등으로 구 성된다고 하였고, Ambrose, Huston, \& Norman (2005)은 직무만족의 요소로서 급여, 멘토링 및 승진기회를 제시했으며, Grant, Christianson., \& Price(2007)은 직원들의 신체적, 정신적 건강과 행 복감 및 사회적 웰빙 등이 직무만족의 조건이 된 다고 하였다.

직무만족에 대한 이론을 발전시킨 Herzberg (1974)는 직무 만족을 일으키는 동기요인(motivator needs)과 위생요인(hygiene needs)을 제시하 였는데, 동기요인은 직무 자체에 대한 만족감으로
성취, 인정, 책임감, 도전감, 성장 가능성 등과 관 련되어 있고 위생요인은 조직의 정책, 보수, 근무 환경, 직업의 안전성, 상사와 동료와의 관계에 관 련되어 있기 때문에 직무만족이 조직의 성과에 많 은 영향을 미친다고 하였다. Porter, Lawler III, \& Hackman(1987)은 직무만족을 조직전체요인 (급여, 승진기회, 회사정책 및 절차, 급여절차 등), 작업환경요인(감독, 의사결정 참여, 작업집단의 규 모, 동료관계, 작업조건 등), 직무내용요인, 개인요 인 등으로 분류하였고, Yoon(2015)은 인간관계요 인, 직무요인, 근무환경 및 외부환경요인으로 직무 만족이 구성된다고 하였다. 이와 같이 직무만족은 다차원으로 구성된 개념으로서 직무자체에 대한 개인의 만족과 근무조건이나 환경, 임금 및 제도 등에 대한 만족 정도를 나타내며, 조직의 구조나 규모, 조직 특성과 문화 및 리더십 등에 의해 직 무만족이 다르게 나타날 뿐 아니라 조직의 성과를 높이는데 크게 기여할 수 있다.

직무만족에 관한 선행연구에서는 직무만족에 영향을 미치는 요인으로 조직문화(Belias \& Koustelios, 2014; K. S. Kim, 2015), 조직 공정성 (Park, 2016; Park \& Lee, 2012), 직무 적합성 (Kim, 2014; Kim, Kim, \& Park, 2008), 리더십 (Ryu \& Shin, 2013; Yang \& Choi, 2012) 등을 논의해 왔으며, $\mathrm{Seo}(2015)$ 의 연구에 의하면 진정 성 리더십이 직무만족을 높이는 것으로 나타났다. Leroy, Anseel, Gardner, \& Sels(2015)는 진정성 리더십과 진정성 팔로우십, 직무 역할 만족에 관 한 연구를 수행하였고, Choi \& Lee(2009)는 패션 기업 팀장의 카리스마 리더십과 조건적 보상, 지 적 자극, 개인적 배려 리더십이 팀원의 직무만족 에 영향을 미친다고 밝혔으며, Shin \& Soh(2015) 는 패션 디자이너의 직무만족을 업무만족, 고용만 족, 관계만족으로 나누고 조율가형 리더조직이 패 션디자이너의 직무만족에 중요한 조직유형이라고 하였다. 또한 Hong(2010)에 의하면 패션기업 CEO 의 상황적 보상 리더십과 카리스마 리더십, 개별 
적 배려 리더십이 $\mathrm{CEO}$ 에 대한 직원들의 신뢰를 높여 직무만족에 영향을 미치는 것으로 나타났으 므로 패션기업 $\mathrm{CEO}$ 의 리더십은 직원들의 직무만 족을 높이는 요인이라고 할 수 있다.

\section{3. 조직성과}

조직성과는 조직이 내세운 목표의 성취도이며 (Lee, 2009), '조직 구성원들이 실현하고자 하는 일의 바람직한 상태 혹은 목표를 달성할 수 있는 정도(Tett \& Meyer, 1993)'를 나타낸다. Hong (2012)은 조직성과를 조직 내에서 발생하는 재무 적, 비재무적 성과에 대해 조직 구성원들이 느끼 고 생각하는 정도라고 하였고, Brewer \& Selden (2000)은 조직 수준과 개인 수준에서 조직성과를 예측할 수 있다고 하였으며, Oczkowski \& Farrell (1998)은 기업의 성과에 대하여 신제품 성과, 고 객유치, 투자대비 이익, 판매증가율 및 비 재무적 인 전반적인 성과들이 포함된다고 하였다. $\mathrm{Kim}$ \& Yang(2015)은 기업성과가 직무성과와 신제품 성과, 경영성과로 구성된 개념이라고 하였는데, 직 무성과는 조직 내에서 구성원이 자신이 맡은 직무 를 수행해 낸 성과를 나타내고, 신제품성과는 기 업이 지속적인 성장, 발전하기 위한 신제품 개발 혁신을 성공적으로 이뤄내는 것을 의미하며, 경영 성과는 기업의 목표달성을 위한 구체적인 성과인 효과성과 경영과정에서 투입량 대비 산출량을 나 타내는 효율성을 포함하는 것이라고 하였다.

조직의 성과는 기업의 전략과 조직 구성원의 역량 및 직무만족에 따라 달라질 수 있으며, $\mathrm{CEO}$ 의 철학과 리더십에 의해서도 다르게 나타날 수 있다. Yammarino, Dionne, Schriesheim, \& Dansereau(2008)는 진정성 리더십이 긍정적 조직행동 과 업무성과를 촉진한다고 하였고, Davish \& Rezaei(2011)는 리더의 진정성 리더십에 대한 구 성원들의 인식이 직무만족과 팀 몰입에 긍정적으 로 관련되어 있어 성과를 높일 수 있다고 하였으 며, Wong \& Laschinger(2012)는 투명성, 공정성,
자아인식과 높은 도덕적 기준을 강조하는 진정성 있는 리더들이 직원들의 업무성과와 직무만족을 향 상시킨다고 하였다. Park \& Kwon(2010)과 Jang, $\mathrm{Kim}, \& \mathrm{Choi}(2016)$ 의 연구에서는 종사원의 직무 만족으로 인해 조직의 성과가 높아진다고 나타났 으며, Lee \& Cha(2015)는 진정성 리더십이 조직 구성원들의 조직동일시와 직무성과 및 이직의도에 직접적인 영향을 미친다고 하였다. Koo \& Lee (2014)는 진정성 리더십이 종사원의 직무만족에 정 $(+)$ 의 영향을 미치고, 직무만족이 계산적 몰입 과 지속적 몰입, 그리고 직무성과에 정 $(+)$ 의 영향 을 미친다고 하였다.

패션분야의 조직성과에 관한 연구를 살펴보면, $\operatorname{Kim}(2002)$ 은 패션 머천다이저의 상향식 개방의사 소통과 업무와 지위에 대한 만족이 조직성과에 영 향을 미친다고 하였고, Choi(2010)는 패션업체의 내부마케팅 요인과 임금 및 승진, 직무자체, 동료 관계에 대한 만족이 판매사원의 직무성과에 영향 을 미친다고 하였다. Choi, Lee, \& Hwang(2014) 은 패션업체 판매원의 임파워먼트가 보상적 만족 을 통해 직무성과를 높인다고 하였으며, $\mathrm{Kim} \&$ Yang(2015)은 패션기업 $\mathrm{CEO}$ 의 감성적 관계관리 능력, 감성적 사회적 인식능력, 감성적 자기인식능 력, 감성적 자기관리능력의 리더십이 높을수록 직 원의 직무에 대한 보람과 만족도 및 발전과 성장 의 기회, 창의력 발휘 등을 통한 직무성과가 높아 진다고 하였다. 이와 같이 패션분야의 조직성과에 관한 연구는 다양한 요인을 다루고 있으며, 본 연 구에서는 패션기업 $\mathrm{CEO}$ 의 진정성 리더십과 직무 만족이 조직성과에 미치는 영향을 분석하고자 하 였다. 또한 기업 규모에 따라 직무만족과 성과가 달라지고(I. S. Kim, 2015), 기업의 유형별로 리더 십에 대한 인식도 다른 것 $(\mathrm{Kim}, 2012)$ 으로 밝혀 지고 있어 패션기업의 규모에 따른 진정성 리더십 과 직무만족 및 조직성과의 차이를 분석하고자 하 였다. 


\section{III. 연구방법 및 절차}

\section{1. 연구문제}

본 연구는 패션기업 $\mathrm{CEO}$ 의 진정성 리더십과 직원의 직무만족 및 조직성과 간의 영향관계와 기 업규모별 차이를 분석하고자 다음과 같은 연구문 제를 설정하였다.

연구문제1. 패션기업 $\mathrm{CEO}$ 의 진정성 리더십이 직원의 직무만족에 미치는 영향을 분석한다.

연구문제2. 패션기업 직원의 직무만족이 조직성 과에 미치는 영향을 분석한다.

연구문제3. 패션기업 $\mathrm{CEO}$ 의 진정성 리더십이 조직성과에 미치는 영향을 분석한다.

연구문제4. 패션기업의 규모에 따fms $\mathrm{CEO}$ 의 진정성 리더십과 직무만족 및 조직성과의 차이를 분석한다.

\section{2. 설문지 구성}

본 연구의 설문지는 패션기업 $\mathrm{CEO}$ 의 진정성 리더십과 직무만족 및 조직성과에 관한 문항과 기 업규모 및 개인적 특성에 관한 문항으로 구성하였 다. 패션기업 $\mathrm{CEO}$ 의 진정성 리더십은 Avolio \& Gardner(2005), Illies et al.(2005), Walumbwa et al.(2008), Koo \& Lee(2014) 등의 연구를 참조하 여 자아 인식, 관계적 투명성, 균형적 정보처리로 서의 공정성, 긍정적 윤리성 및 미래지향성에 관 한 25문항으로 구성하였으며, 이들 항목은 '매우 낮음'을 1점으로, '매우 높음'을 5점으로 하는 5점 리커트 척도로 측정하였다. 직무만족은 Antoncic \& Antoncic(2011), Shin \& Soh(2015), Yoon(2015) 등의 연구를 참고하여 직무 자체, 임금 및 제도, 근로조건 및 환경의 만족 정도에 관한 18 문항으로 구성하였으며, 이들 항목은 '매우 낮음'을 1점으로, '매우 높음'을 5점으로 하는 5점 리커트 척도로 측 정하였다. 조직성과는 Lee \& Cha(2015), Kim \& Yang(2015) 등의 연구를 참고하여 경영성과와 신
상품성과, 직무성과에 관한 18 문항으로 구성하였 으며, 이들 항목은 '매우 낮음'을 1점으로, '매우 높음'을 5점으로 하는 5점 리커트 척도로 측정하 였다. 또한 패션기업의 규모에 관한 문항과 개인 적 특성으로서 성별, 연령, 결혼여부, 학력, 연봉, 근무부서, 직책 및 재직기간에 관한 문항은 명목 척도로 측정하였다.

\section{3. 자료수집 및 분석}

본 연구는 서울 수도권 지역 패션기업의 직원 을 대상으로 설문조사를 실시하였고, 자료 수집을 위하여 예비조사와 본 조사의 2가지 방법을 진행 하였다. 예비조사는 2016년 6월 1일에서 6월 20일 사이에 실시하였으며, 80 부의 자료를 분석하여 설 문지를 수정 및 보완하였다. 본 조사에서는 2016 년 7월 1 일에서 8 월 30 일까지 두 달 동안 450 부의 자료를 수집하였으며, 응답이 불성실한 10 부의 자 료를 제외하고 440 부의 자료를 분석에 사용하였 다. 자료 분석은 SPSS 21.0 프로그램을 이용하여 다음과 같이 분석하였다. 첫째, 연구대상의 인구통 계학적 특성과 기업특성은 빈도분석(frequency analysis)을 실시하였고, 둘째, 패션기업 $\mathrm{CEO}$ 의 진정성 리더십과 직무만족, 조직성과를 구성하는 측정도구의 타당성과 신뢰성은 Kaiser 규칙이 있 는 직각회전방식인 Varimax 회전을 이용한 주성 분 요인분석(principal component factor analysis) 과 신뢰성 분석(reliability analysis)으로 검증하였 다. 셋째, 패션기업 $\mathrm{CEO}$ 의 진정성 리더십과 직무 만족, 조직성과 간의 영향관계는 다중회귀분석 (multiple regression analysis)을 실시하였고, 넷째, 패션기업의 규모에 따른 차이는 ANOVA로 분석 하였으며, 사후검증방법으로 Scheffé test를 사용 하였다.

\section{4. 연구대상의 특성}

본 연구의 대상이 근무하는 패션기업의 규모는 
대기업 $8.4 \%$ (37명), 중견기업 33.0\%(145명), 중소 기업 58.6\%(258명)로서 중소기업이 가장 많았다. 여기서 대기업은 자산규모 10 조원 이상인 기업이 고, 중견기업은 상시 근로자 1,000 명 이상, 자기자 본 1,000 억원 이상, 3 년 평균 매출 1,500 억원 이상 가운데 하나라도 해당되는 기업을 말하며, 중소기 업은 종견기업의 조건에 해당사항이 없는 기업을 나타낸다. 이들 기업에 근무하는 연구대상의 특성 을 분석한 결과, 성별은 남자 $57.7 \%$ (254명), 여자 $42.3 \%$ (186명)이었고, 연령은 20 대 $21.1 \%$ (93명), 30 대 47.8\%(210명), 40대 25.0\%(110명), 50대 이 상 $6.1 \%$ (27명)이었으며, 결혼여부는 미혼 $55.7 \%$ (245명), 기혼 $44.3 \%$ (195명)의 결과를 보였다. 학 력은 고등학교 졸업 $9.5 \%$ (42명), 전문대학교 졸업 $18.6 \%$ (82명), 대학교 졸업 이상 $71.9 \%(316$ 명)로 4년제 대학교 졸업이상이 대부분이었으며, 연봉은 3 천만원 미만 $21.8 \%$ (96명), 3 천만원 4 천만원 미 만 $38.4 \%$ (169명), 4 천만원 5천만원 미만 $21.1 \%$ (93 명), 5 천만원 6 천만원 미만 $9.5 \%$ (42명), 6 천만원 이상 $9.1 \%$ (40명)로 응답자의 $60 \%$ 정도가 4 천만 원 미만의 연봉을 받고 있었다. 근무부서는 디자 인 $18.4 \%$ (81명), $\mathrm{MD} /$ 상품기획 $18.2 \%$ (80명), 영업 $29.1 \%$ (128명), 마케팅 $8.4 \%$ (37명), 관리 $15.2 \%$ (67명), 생산 5.7\%(25명), 물류 5.0\%(22명)이었으 며, 직책은 사원 27.5\%(121명), 대리 28.6\%(126 명), 과장 $23.2 \%(102$ 명), 차장/부장 $20.7 \%$ (91명) 로 나타났다. 재직기간은 1 년 미만 $18.2 \%$ (80명), 1년 3년 미만 34.5\%(152명), 3년 5년 미만 $28.2 \%$ (124명), 5년 7년 미만 8.9\%(39명), 7년 이 상 $10.2 \%$ (45명)로 1년 5년 미만의 응답자가 전 체의 $62.7 \%$ 로 나타났다.

\section{IV. 연구결과 및 논의}

\section{1. 패션기업 $\mathrm{CEO}$ 의 진정성 리더십과 직무만족 및 조직성과의 구성요인}

본 연구는 측정변수의 구성요인을 밝히고 타당
성과 신뢰성을 검증하기 위하여 요인분석과 신뢰성 분석을 실시하였다. 요인분석에서는 고유값(Eigen value) 1.0 이상, 요인 적재량(factor loading) 0.5 이 상을 유효한 변수로 하여 요인을 추출하였으며, 신뢰성 분석에서는 Cronbach's a 계수를 산출하여 이 값이 0.6 이상일 경우 신뢰성이 있다고 판단하 였다.

\section{1) 패션기업 $\mathrm{CEO}$ 의 진정성 리더십}

패션기업 $\mathrm{CEO}$ 의 진정성 리더십은 25 문항으로 구성하였고, 이들 문항의 요인분석을 실시한 결과 〈Table 1〉과 같이 5 개의 요인이 도출되었다. 요인 1 은 $\mathrm{CEO}$ 가 직원들의 의견을 존중하거나 융통성 있게 받아들이고, 공개적으로 직원들과 정보를 공 유할 뿐 아니라 강점과 약점까지도 노출하면서 투 명하게 기업을 이끄는 리더십과 관련되어 있어 '투명성'이라 하였다. 요인 2는 CEO가 5년 내지 10 년 내에 달성할 목표를 가지고 일을 하거나 단 기적 수익을 추구하기보다는 지속적인 회사의 성 장을 위해 노력하고 장기적인 목표나 비전을 제시 하고 독려하는 미래지향적인 리더십과 관련되어 있어 '미래지향성'이라 하였으며, 요인 3은 $\mathrm{CEO}$ 가 자신의 감정을 솔직하게 표현하고 자신의 능력을 잘 알고 있다는 등의 자아인식에 관한 내용을 포 함하고 있어 '자아인식'이라 하였다. 요인 4 는 $\mathrm{CEO}$ 가 결정을 하기 전에 직원들의 다양한 의견 이 귀를 기울이고 관련 정보를 객관적으로 분석한 다는 내용을 포함하고 있어 '공정성'이라 하였으 며, 요인 5 는 $\mathrm{CEO}$ 가 자신의 도덕적 가치관에 따 라 행동하고 윤리적 책임의식을 중시하는 도덕적 관점에서의 리더십과 관련되어 있어 '윤리성'이라 하였다. 이들 요인의 총 분산은 $77.955 \%$ 였으며, 각 요인의 평균은 투명성 3.197, 미래지향성 3.371, 자아인식 3.377, 공정성 3.209, 윤리성 3.346으로서 자아인식의 평균이 가장 높았다. 신뢰성분석 결과 에 따른 Cronbach's a계수는 투명성 .933, 미래지 향성 .929 , 자아인식 .848 , 공정성 .761 , 윤리성 
$\langle$ Table 1〉 Factor analysis and reliability analysis on authentic leadership

\begin{tabular}{|c|c|c|c|c|c|}
\hline Factors & Measured items & $\begin{array}{c}\text { Factor } \\
\text { loadings }\end{array}$ & $\begin{array}{l}\text { Eigen } \\
\text { value }\end{array}$ & $\begin{array}{c}\text { Cumulative } \\
\%\end{array}$ & $\begin{array}{c}\text { Cronbach's } \\
\text { a }\end{array}$ \\
\hline \multirow{7}{*}{$\begin{array}{l}\text { Transpa- } \\
\text { rency }\end{array}$} & My CEO knows to accept the employee's loyalty comments. & .857 & \multirow{7}{*}{4.612} & \multirow{7}{*}{21.962} & \multirow{7}{*}{.933} \\
\hline & My CEO respects the employee's opinions. & .761 & & & \\
\hline & My CEO admits his mistakes frankly. & .707 & & & \\
\hline & My CEO has the flexibility to accept the employee's opinions. & .623 & & & \\
\hline & $\begin{array}{l}\text { My CEO makes even encouraged employee to claim the } \\
\text { opposite point of view. }\end{array}$ & .615 & & & \\
\hline & $\begin{array}{l}\text { My CEO expose even his own strengths and weaknesses to } \\
\text { his employees. }\end{array}$ & .576 & & & \\
\hline & My CEO shares information openly with employees. & .535 & & & \\
\hline \multirow{5}{*}{$\begin{array}{c}\text { Future } \\
\text { orientation }\end{array}$} & My CEO has the goal to be achieved within 5 to 10 years. & .796 & \multirow{5}{*}{4.337} & \multirow{5}{*}{42.616} & \multirow{5}{*}{.929} \\
\hline & $\begin{array}{l}\text { My CEO is committed to the continuous growth of the } \\
\text { company, rather than pursuing short-term profits. }\end{array}$ & .765 & & & \\
\hline & $\begin{array}{l}\text { My CEO has his own philosophy and suggests company } \\
\text { direction precisely. }\end{array}$ & .759 & & & \\
\hline & $\begin{array}{l}\text { My CEO is encouraging employees with long-term goal and } \\
\text { vision. }\end{array}$ & .756 & & & \\
\hline & $\begin{array}{l}\text { My CEO decides what to do now to consider what will } \\
\text { happen in the future. }\end{array}$ & .660 & & & \\
\hline \multirow{4}{*}{$\begin{array}{c}\text { Self- } \\
\text { awareness }\end{array}$} & My CEO communicates clearly what he wants to say. & .800 & \multirow{4}{*}{3.494} & \multirow{4}{*}{59.252} & \multirow{4}{*}{.848} \\
\hline & My CEO express his feeling frankly. & .753 & & & \\
\hline & My CEO is well aware of his ability. & .660 & & & \\
\hline & My CEO knows well how to evaluate him among employees. & .652 & & & \\
\hline \multirow{2}{*}{$\begin{array}{c}\text { Balanced } \\
\text { process }\end{array}$} & $\begin{array}{l}\text { My CEO listen to various opinions of employees before } \\
\text { making decision. }\end{array}$ & .792 & \multirow{2}{*}{2.199} & \multirow{2}{*}{69.724} & \multirow{2}{*}{.761} \\
\hline & $\begin{array}{l}\text { My CEO analysis the relevant information with an objective } \\
\text { way before making decision. }\end{array}$ & .563 & & & \\
\hline \multirow{3}{*}{ Ethicality } & $\begin{array}{l}\text { My CEO acts and decides accordance with his own moral } \\
\text { values. }\end{array}$ & .699 & \multirow{3}{*}{1.729} & \multirow{3}{*}{77.955} & \multirow{3}{*}{.839} \\
\hline & $\begin{array}{l}\text { My CEO doesn't compromise his belief when he is forced to } \\
\text { work against his belief. }\end{array}$ & .575 & & & \\
\hline & My CEO is focused on ethical responsibility. & .565 & & & \\
\hline
\end{tabular}

.839로서 신뢰수준이 높게 나타났다.

\section{2) 직무만족}

패션기업 직원들의 직무만족에 대한 18 문항을 요인분석한 결과에서는 〈Table 2〉와 같이 3 개의 요인이 도출되었다. 요인 1 은 회사의 급여체계, 임 금 인상 기회, 승진제도, 정당한 대우와 권한 부여
등에 대한 만족도 문항으로 구성되어 있어 '임금 및 제도 만족’이라 하였고, 요인 2는 업무를 통한 보람과 성취감, 성장과 발전, 업무에 대한 자긍심 과 전반적인 만족도 문항으로 구성되어 있어 '직 무 자체 만족'이라 하였으며, 요인 3은 회사의 청 결, 위생 상태와 근무환경, 부서 간의 원활한 업무 협조, 동료 및 상사와의 관계 등에 대한 만족도 
문항으로 구성되어 있어 '근무조건 및 환경 만족' 이라 하였다. 이들 요인의 총 변량은 $70.942 \%$ 였으 며, 각 요인의 평균은 임금 및 제도 만족 2.870 , 직무 자체 만족 3.553 , 근무조건 및 환경 만족 3.283 으로서 직무 자체 만족의 평균이 가장 높았 다. 신뢰성분석 결과에 따른 Cronbach's a계수는 임금 및 제도 만족 .929 , 직무 자체 만족 .898 , 근 무조건 및 환경 만족 .875로서 신뢰수준이 높게 나타났다.

\section{3) 조직성과}

패션기업의 조직성과에 대한 18 문항을 요인분
석한 결과에서는〈Table 3 〉과 같이 3 개의 요인이 도출되었다. 요인 1 은 회사의 매출액과 수익, 시장 점유율 및 신규 고객의 지속적인 증가와 대내외적 이미지 상승에 대한 문항을 포함하고 있어 '경영 성과라 하였고, 요인 2는 신상품 개발을 위한 적 극적인 $\mathrm{R} \& \mathrm{D}$ 투자, 신상품 프로모션, 원부자재 확 보 및 시장조사 등에 관한 문항을 포함하고 있어 '신상품성과'라 하였으며, 요인 3은 우수한 업무 적응 능력과 성과, 업무관련 지식 및 숙련도 등에 대한 문항을 포함하고 있어 '직무성과'라 하였다. 이들 요인의 총 변량은 $76.343 \%$ 였으며, 각 요인의 평균은 경영성과 3.191 , 신상품성과 3.014 , 직무성

$\langle$ Table 2〉 Factor analysis and reliability analysis on job satisfaction

\begin{tabular}{|c|c|c|c|c|c|}
\hline Factors & Measured items & $\begin{array}{c}\text { Factor } \\
\text { loadings }\end{array}$ & $\begin{array}{l}\text { Eigen } \\
\text { value }\end{array}$ & \begin{tabular}{c|} 
Cumulative \\
$\%$
\end{tabular} & $\begin{array}{c}\text { Cronbach's } \\
\text { a }\end{array}$ \\
\hline \multirow{6}{*}{$\begin{array}{l}\text { Wages or } \\
\text { system } \\
\text { satisfaction }\end{array}$} & My company payroll system is adequate. & .899 & \multirow{6}{*}{4.909} & \multirow{6}{*}{28.878} & \multirow{6}{*}{.929} \\
\hline & $\begin{array}{l}\text { I am satisfied with the wage increases opportunities of } \\
\text { my company. }\end{array}$ & .886 & & & \\
\hline & I am satisfied with the promotion system of my company. & .859 & & & \\
\hline & $\begin{array}{l}\text { I am satisfied with the fair treatment and authorization } \\
\text { system of my company. }\end{array}$ & .836 & & & \\
\hline & I am satisfied on reasonable wage policy of my company. & .808 & & & \\
\hline & $\begin{array}{l}\text { I am satisfied with the stable employment guarantee } \\
\text { system of my company. }\end{array}$ & .649 & & & \\
\hline \multirow{6}{*}{$\begin{array}{l}\text { Job itself } \\
\text { satisfaction }\end{array}$} & My job undertaken in my company is the one that I like. & .828 & \multirow{6}{*}{4.144} & \multirow{6}{*}{53.257} & \multirow{6}{*}{.898} \\
\hline & $\begin{array}{l}\text { I feel the sense of worth and accomplishment through } \\
\text { my job. }\end{array}$ & .794 & & & \\
\hline & I have a sense of pride about my job. & .765 & & & \\
\hline & My job is helpful for my growth and development. & .751 & & & \\
\hline & I am satisfied with my job generally. & .745 & & & \\
\hline & $\begin{array}{l}\text { I think that while performing my jobs improve my } \\
\text { competitiveness. }\end{array}$ & .703 & & & \\
\hline \multirow{5}{*}{$\begin{array}{c}\text { Working } \\
\text { condition or } \\
\text { environmental } \\
\text { satisfaction }\end{array}$} & $\begin{array}{l}\text { I am satisfied with the cleanliness, sanitary condition of } \\
\text { my company. }\end{array}$ & .848 & \multirow{5}{*}{3.006} & \multirow{5}{*}{70.942} & \multirow{5}{*}{.875} \\
\hline & $\begin{array}{l}\text { I am satisfied with the smooth and cooperation between } \\
\text { my department and other departments. }\end{array}$ & .726 & & & \\
\hline & $\begin{array}{l}\text { I am satisfied with the relationship with colleagues and } \\
\text { superiors of my company. }\end{array}$ & .712 & & & \\
\hline & I am satisfied with the work environment of my company. & .601 & & & \\
\hline & I am satisfied with the work load of my company. & .505 & & & \\
\hline
\end{tabular}


〈Table 3〉 Factor and reliability analysis on organizational performance

\begin{tabular}{|c|c|c|c|c|c|}
\hline Factors & Measured items & $\begin{array}{c}\text { Factor } \\
\text { loadings }\end{array}$ & $\begin{array}{l}\text { Eigen } \\
\text { value }\end{array}$ & \begin{tabular}{|c|} 
Cumulative \\
$\%$
\end{tabular} & $\begin{array}{c}\text { Cronbach's } \\
\text { a }\end{array}$ \\
\hline \multirow{6}{*}{$\begin{array}{l}\text { Management } \\
\text { performance }\end{array}$} & My company's turnover is constantly increasing. & .898 & \multirow{6}{*}{4.819} & \multirow{6}{*}{26.772} & \multirow{6}{*}{.947} \\
\hline & My company's operating income is constantly increasing. & .893 & & & \\
\hline & My company's turnover is constantly increasing. & .866 & & & \\
\hline & My company's cash flow is improving constantly. & .808 & & & \\
\hline & The reputation of my company is getting better constantly. & .803 & & & \\
\hline & New customer of my company is constantly increasing. & .733 & & & \\
\hline \multirow{6}{*}{$\begin{array}{c}\text { New } \\
\text { product } \\
\text { performance }\end{array}$} & $\begin{array}{l}\text { My company invests in } R \& D \text { for a quick turnover of } \\
\text { new products. }\end{array}$ & .853 & \multirow{6}{*}{4.623} & \multirow{6}{*}{52.457} & \multirow{6}{*}{.946} \\
\hline & $\begin{array}{l}\text { My company is actively engaged in marketing campaigns } \\
\text { to promote new products. }\end{array}$ & .853 & & & \\
\hline & $\begin{array}{l}\text { My company is making efforts to secure raw and secondary } \\
\text { materials required for development of new products. }\end{array}$ & .827 & & & \\
\hline & $\begin{array}{l}\text { My company is actively releasing new products to the } \\
\text { market. }\end{array}$ & .814 & & & \\
\hline & $\begin{array}{l}\text { My company is strengthening the research staff for } \\
\text { development of new products. }\end{array}$ & .779 & & & \\
\hline & $\begin{array}{l}\text { My company is actively doing the market research for } \\
\text { release of new products. }\end{array}$ & .717 & & & \\
\hline \multirow{6}{*}{$\begin{array}{c}\text { Job } \\
\text { performance }\end{array}$} & I think that I have the excellent work adaptability. & .837 & \multirow{6}{*}{4.299} & \multirow{6}{*}{76.343} & \multirow{6}{*}{.911} \\
\hline & I have a high work-related knowledge and skill. & .829 & & & \\
\hline & I produce the better result than CEO's expectation. & .814 & & & \\
\hline & I do my job exactly right way without mistakes. & .781 & & & \\
\hline & I achieve enough job performance in my company. & .778 & & & \\
\hline & I have been a good evaluation for job performance. & .775 & & & \\
\hline
\end{tabular}

과 3.439 로서 직무성과의 평균이 가장 높았다. 신 뢰성분석 결과에 따른 Cronbach's a계수는 경영성 과 .947, 신상품성과 .946, 직무성과 .911로서 신뢰 수준이 높게 나타났다.

\section{2. 패션기업 $\mathrm{CEO}$ 의 진정성 리더십이 직무만족에 미치는 영향}

본 연구에서는 패션기업 $\mathrm{CEO}$ 의 진정성 리더십 이 직원들의 직무만족에 미치는 영향을 분석하기 위하여 진정성 리더십의 요인을 독립변수로 하고, 직무만족의 요인을 종속변수로 하여 회귀분석을 실시하였다. 그 결과〈Table 4〉와 같이 임금 및
제도 만족에 대해서는 진정성 리더십의 모든 요인 이 영향을 미치는 것으로 나타났다. 진정성 리더 십의 투명성 $(\beta=.339, \mathrm{t}=8.187, p \chi .001)$, 공정성 $(\beta$ $=.326, \mathrm{t}=7.863, \not \chi .001)$, 미래지향성 $(\beta=.117, \mathrm{t}=$ $2.829, p \times .01)$, 윤리성 $(\beta=.110, \mathrm{t}=2.662, p \chi .01)$, 자 아인식 $(\beta=.093, \mathrm{t}=2.247, p \nless .05)$ 의 순으로 임금 및 제도 만족에 정 $(+)$ 의 영향을 미치고 있었고, 전체 설명력은 $25.6 \%$ 였다. 따라서 패션기업 $\mathrm{CEO}$ 의 진정성 리더십이 높을수록 직원들의 임금 및 제도에 대한 만족도가 높아진다고 할 수 있다.

직무 자체 만족에 대해서는 진정성 리더십의 자아인식 $(\beta=.324, \mathrm{t}=7.577, p<.001), \quad$ 미래지향성 
$(\beta=.244, \mathrm{t}=5.723, p<.001), \quad$ 투명성 $(\beta=.177, \mathrm{t}=$ $4.136, p<.001)$, 윤리성 $(\beta=.112, \mathrm{t}=2.621, p<.01)$ 의 순으로 정 $(+)$ 의 영향을 미치고 있었고, 전체 설명 력이 $20.8 \%$ 이었다. 이 결과는 패션기업 $\mathrm{CEO}$ 가 자신의 존재를 구별하고 이해할 수 있는 능력이 높을수록, 장기적인 성장과 비전, 직원들과의 투명 한 관계를 중시하거나 윤리와 도덕관점을 중시할 수록 직무에 대한 직원들의 만족정도가 높아짐을 나타낸다. 그러나 공정성은 직무 자체 만족에 영 향을 미치지 않고 있었으므로 $\mathrm{CEO}$ 가 어느 한 쪽 에 편향되지 않고 객관적이고 공정한 의사결정을 한다고 해서 직원들의 직무 만족도가 높아지는 것 은 아니라고 할 수 있다.

근무조건 및 환경 만족에 대해서는 진정성 리 더십의 미래지향성 $(\beta=.377, \mathrm{t}=8.915, p \times .001)$, 투 명성 ( $\beta=.258, \mathrm{t}=6.094, p \chi .001)$, 자아인식 $(\beta=.093$, $\mathrm{t}=2.206, p \times .05)$ 의 순으로 정 $(+)$ 의 영향을 미치고 있었고, 전체 설명력은 $22.4 \%$ 로 나타났다. 따라서 패션기업 $\mathrm{CEO}$ 가 미래지향적인 리더십을 지닐수
록, 직원들과의 관계를 투명하게 하거나 자기 스 스로를 인식하고 이해하는 능력이 높을수록 근무 조건 및 환경에 대한 직원들의 만족정도가 높아진 다고 할 수 있다.

이상의 결과는 진정성 리더십이 직무만족을 높이 는 요인이라고 주장한 선행연구(Seo, 2015; Wong \& Laschinger, 2012)와 유사한 맥락에서 접근할 수 있으나, 패션기업 직원들의 직무만족에 대해서 는 조직유형(Shin \& Soh, 2015), 변혁적 리더십 (Choi \& Lee, 2009; Hong, 2010) 등의 영향력이 밝혀진데 비해 진정성 리더십을 다룬 연구가 수행 되지 않았다는 점에서 본 연구의 결과는 선행연구 와 차별된다.

\section{3. 패션기업 직원의 직무만족이 조직성과에 미치는 영향}

패션기업 직원의 직무만족이 조직성과에 미치 는 영향을 분석하기 위하여 직무만족의 요인을 독

$\langle$ Table 4$\rangle$ The effect of authentic leadership on job satisfaction

\begin{tabular}{|c|c|c|c|c|c|}
\hline Dependent variable & Independent variable & $\beta$ & $t$ & $F$ & $R^{2}$ \\
\hline \multirow{5}{*}{$\begin{array}{l}\text { Wages or } \\
\text { system } \\
\text { satisfaction }\end{array}$} & Transparency & .339 & $8.187 * * *$ & \multirow{5}{*}{$29.796^{* * *}$} & \multirow{5}{*}{.256} \\
\hline & Future orientation & .117 & $2.829^{* *}$ & & \\
\hline & Self-awareness & .093 & $2.247^{*}$ & & \\
\hline & Balanced process & .326 & $7.863^{* * *}$ & & \\
\hline & Ethicality & .110 & $2.662 * *$ & & \\
\hline \multirow{5}{*}{$\begin{array}{c}\text { Job itself } \\
\text { satisfaction }\end{array}$} & Transparency & .177 & $4.136^{* * *}$ & \multirow{5}{*}{$22.826^{* * *}$} & \multirow{5}{*}{.208} \\
\hline & Future orientation & .244 & $5.723^{* * *}$ & & \\
\hline & Self-awareness & .324 & $7.577^{* * *}$ & & \\
\hline & \begin{tabular}{|l} 
Balanced process \\
\end{tabular} & -.002 & -.039 & & \\
\hline & Ethicality & .112 & $2.621 *$ & & \\
\hline \multirow{5}{*}{$\begin{array}{l}\text { Working condition } \\
\text { or environmental } \\
\text { satisfaction }\end{array}$} & Transparency & .258 & $6.094^{* * *}$ & \multirow{5}{*}{$25.058^{* * *}$} & \multirow{5}{*}{.224} \\
\hline & Future orientation & .377 & $8.915^{* * *}$ & & \\
\hline & Self-awareness & .093 & $2.206^{*}$ & & \\
\hline & Balanced process & .000 & -.001 & & \\
\hline & Ethicality & .082 & 1.951 & & \\
\hline
\end{tabular}

${ }^{*} p \nmid .05,{ }^{* *} p \nmid .01,{ }^{* * *} p \nmid\langle .001$ 
립변수로 하고 조직성과의 요인을 종속변수로 하 여 회귀분석을 실시한 결과는〈Table 5〉와 같다. 경영성과에 대해서는 임금 및 제도 만족 $(\beta=.442$, $\mathrm{t}=10.744, p \times .001)$, 근무조건 및 환경 만족 $(\beta$ $=.256, \mathrm{t}=6.212, p(001)$ 의 순으로 정 $(+)$ 의 영향 을 미치고 있었고, 전체 설명력은 $26.2 \%$ 로 나타났 다. 따라서 패션기업에서 임금에 대한 적절한 대 우와 권한 부여, 근무조건 및 환경 등을 통해 직 원들의 만족도를 높일수록 경영성과가 높아짐을 알 수 있다.

신상품성과에 대해서는 근무조건 및 환경 만족 $(\beta=.473, \mathrm{t}=12.043, p \times .001)$, 임금 및 제도 만족 $(\beta=.262, t=6.681, p \times .001)$, 직무 자체 만족 $(\beta$ $=.186, \mathrm{t}=4.738, p(001)$ 의 순으로 정 $(+)$ 의 영향 을 미치고 있었으며, 전체 설명력이 $32.7 \%$ 이었다. 직무성과에 대해서는 직무 자체 만족 $(\beta=.361$, $\mathrm{t}=8.177, p \times .001)$, 근무조건 및 환경 만족 $(\beta=.102$, $\mathrm{t}=2.309, \quad p \times .05), \quad$ 임금 및 제도 만족 $(\beta=.097$, $\mathrm{t}=2.203, p<.05)$ 의 순으로 정 $(+)$ 의 영향을 미치고 있었고, 전체 설명력은 $15.0 \%$ 로 나타났다. 특히 근무조건 및 환경 만족이 신상품성과에 미치는 영 향력이 가장 높았고, 직무 자체 만족이 직무성과 에 미치는 영향력이 가장 높게 나타났으며, 패션 기업 직원들의 직무만족이 높을수록 신상품성과와
직무성과가 높아지고 있었다.

이상의 결과는 조직 구성원의 직무만족으로 인 해 조직의 성과가 높아진다고 밝힌 선행연구(Jang et al., 2016; Park \& Kwon, 2010)를 지지하였으 나, 이들 연구는 병원이나 호텔 종사원을 대상으로 분석한데 비해 본 연구에서 패션기업 직원들을 대 상으로 분석하였다는 점에서 차별된 의의가 있다.

\section{4. 패션기업 $\mathrm{CEO}$ 의 진정성 리더십이 조직성과에 미치는 영향}

패션기업 $\mathrm{CEO}$ 의 진정성 리더십이 조직성과에 미치는 영향을 분석하기 위하여 진정성 리더십의 요인을 독립변수로, 조직성과의 요인을 종속변수 로 하여 회귀분석을 실시한 결과는 〈Table 6〉과 같다. 경영성과에 대해서는 진정성 리더십의 미래 지향성 $(\beta=.339, \mathrm{t}=8.445, p<.001)$, 투명성 $(\beta=.279$, $\mathrm{t}=6.963, \quad p \times .001), \quad$ 윤리성 $(\beta=.265, \quad \mathrm{t}=6.599, \quad p \alpha$ $.001)$, 공정성 $(\beta=.149, \mathrm{t}=3.727, p<.001)$, 자아인식 $(\beta=.133, \mathrm{t}=3.317, p<.01)$ 의 순으로 정 $(+)$ 의 영향 을 미치고 있었고, 전체 설명력은 $30.3 \%$ 이었다. 이 결과는 패션기업 $\mathrm{CEO}$ 의 진정성 리더십이 높 을수록 경영성과가 높아지는 것으로 해석할 수 있 다. 신상품성과에 대해서는 미래지향성 $(\beta=.380$,

$\langle$ Table 5〉 The effect of job satisfaction on organizational performance

\begin{tabular}{|c|c|c|c|c|c|}
\hline $\begin{array}{l}\text { Dependent } \\
\text { variable }\end{array}$ & Independent variable & $\beta$ & $t$ & $F$ & $R^{2}$ \\
\hline \multirow{3}{*}{$\begin{array}{l}\text { Management } \\
\text { performance }\end{array}$} & Wages or system satisfaction & .442 & $10.744^{* * *}$ & \multirow{3}{*}{$51.534^{* * *}$} & \multirow{3}{*}{.262} \\
\hline & Job itself satisfaction & .031 & .764 & & \\
\hline & Working condition or environmental satisfaction & .256 & $6.212^{* * *}$ & & \\
\hline \multirow{3}{*}{$\begin{array}{c}\text { New } \\
\text { product } \\
\text { performance }\end{array}$} & Wages or system satisfaction & .262 & $6.681^{* * *}$ & \multirow{3}{*}{$70.704^{* * *}$} & \multirow{3}{*}{.327} \\
\hline & Job itself satisfaction & .186 & $4.738^{* * *}$ & & \\
\hline & Working condition or environmental satisfaction & .473 & $12.043^{* * *}$ & & \\
\hline \multirow{3}{*}{$\begin{array}{c}\text { Job } \\
\text { performance }\end{array}$} & Wages or system satisfaction & .097 & $2.203^{*}$ & \multirow{3}{*}{$25.682^{* * *}$} & \multirow{3}{*}{.150} \\
\hline & Job itself satisfaction & .361 & $8.177^{* * *}$ & & \\
\hline & Working condition or environmental satisfaction & .102 & $2.309 *$ & & \\
\hline
\end{tabular}

${ }^{*} \not<.05,{ }^{* * *} p \propto .001$ 
$\langle$ Table 6> The effect of authentic leadership on organizational performance

\begin{tabular}{|c|c|c|c|c|c|}
\hline Dependent variable & Independent variable & $\beta$ & $t$ & $F$ & $R^{2}$ \\
\hline \multirow{5}{*}{ Management performance } & Transparency & .279 & $6.963^{* * *}$ & \multirow{5}{*}{$37.649^{* * *}$} & \multirow{5}{*}{.303} \\
\hline & Future orientation & .339 & $8.445^{* * *}$ & & \\
\hline & Self-awareness & .133 & $3.317^{* *}$ & & \\
\hline & Balanced process & .149 & $3.727^{* * *}$ & & \\
\hline & Ethicality & .265 & $6.599 * * *$ & & \\
\hline \multirow{5}{*}{ New product performance } & Transparency & .279 & $6.611^{* * *}$ & \multirow{5}{*}{$25.476^{* * *}$} & \multirow{5}{*}{.227} \\
\hline & Future orientation & .380 & $9.004^{* * *}$ & & \\
\hline & Self-awareness & .028 & .663 & & \\
\hline & Balanced process & -.052 & -1.234 & & \\
\hline & Ethicality & -.034 & -.805 & & \\
\hline \multirow{5}{*}{ Job performance } & Transparency & .047 & 1.010 & \multirow{5}{*}{$5.086^{* * *}$} & \multirow{5}{*}{.055} \\
\hline & Future orientation & .059 & 1.262 & & \\
\hline & Self-awareness & .155 & $3.319^{* *}$ & & \\
\hline & Balanced process & .118 & $2.535^{*}$ & & \\
\hline & Ethicality & .108 & $2.319^{*}$ & & \\
\hline
\end{tabular}

$* p<.05,{ }^{* *} p<.01,{ }^{* * *} p \propto .001$

$\mathrm{t}=9.004, \quad \not \chi 001), \quad$ 투명성 $(\beta=.279, \quad \mathrm{t}=6.611, \quad p<$ $.001)$ 의 순으로 정 $(+)$ 의 영향을 미치고 있었으며, 전체 설명력은 $22.7 \%$ 이었다. 직무성과에 대해서는 자아인식 $(\beta=.155, \mathrm{t}=3.319, \quad p \times .01), \quad$ 공정성 $(\beta=$ $.118, \mathrm{t}=2.535, p \times .05)$, 윤리성 $(\beta=.108, \mathrm{t}=2.319$, $p \chi .05)$ 의 순으로 정 $(+)$ 의 영향을 미치고 있었고, 전체 설명력은 $5.5 \%$ 로 나타났다. 특히 신상품성과 에 대해서는 미래지향성의 영향력이, 직무성과에 대해서는 자아인식의 영향력이 상대적으로 높았으 며, 패션기업 $\mathrm{CEO}$ 가 미래의 장기적인 성장과 비전 에 중점에 둘 뿐 아니라 타인이나 환경으로부터 자 신의 존재를 구별하고 이해하는 능력이 높을수록 신상품성과와 직무성과가 높아진다고 할 수 있다.

이상의 결과는 투명성, 공정성, 자아인식과 높 은 도덕적 기준을 강조하는 진정성 있는 리더들이 직원들의 업무성과를 높인다고 한 Wong \& Laschinger(2012)의 연구와 비슷한 결과였으며, 지금 까지 패션기업의 성과에 대한 $\mathrm{CEO}$ 의 감성적 리 더십을 분석한 연구(Kim \& Yang, 2015)가 수행
된 반면에 본 연구에서는 조직성과에 영향을 미치 는 진정성 리더십 유형을 밝힌 것에 의의가 있다.

\section{5. 패션기업 규모에 따른 $\mathrm{CEO}$ 의 진정성 리더십, 직무만족 및 조직성과의 차이}

패션기업의 규모에 따른 $\mathrm{CEO}$ 의 진정성 리더십, 직무만족, 조직몰입 및 업무성과의 차이를 분석하 기 위해 ANOVA를 실시한 결과는 〈Table 7〉과 같다. 기업규모에 따라서는 $\mathrm{CEO}$ 의 투명성 $(\mathrm{F}=$ $9.508, p<.001)$, 미래지향성 $(\mathrm{F}=59.600, p \nmid .001)$, 자 아인식 $(\mathrm{F}=28.443, p<.001)$, 공정성 $(\mathrm{F}=23.444, p<$ $.001)$, 윤리성 $(\mathrm{F}=16.781, p \nless .001)$ 의 차이를 보였 다. 대기업과 중소기업에 비해 중견기업에서 $\mathrm{CEO}$ 의 투명성과 공정성, 윤리성에 대한 평균이 더 높 았으며, 중소기업보다는 중견기업과 대기업에서 미래지향성과 자아인식에 대한 평균이 더 높았다. $\mathrm{CEO}$ 의 미래지향성과 자아인식에 대한 평균은 대 기업에서 가장 높았고, 투명성과 공정성, 윤리성에 
〈Table 7〉 The differences in authentic leadership, job satisfaction and organizational performance by fashion companies' size

\begin{tabular}{|c|c|c|c|c|c|c|c|c|}
\hline & \multirow[t]{2}{*}{ Classification } & \multicolumn{2}{|c|}{$\begin{array}{l}\text { Large-size } \\
\text { company } \\
(\mathrm{n}=37)\end{array}$} & \multicolumn{2}{|c|}{$\begin{array}{l}\text { Mid-size } \\
\text { company } \\
(n=145)\end{array}$} & \multicolumn{2}{|c|}{$\begin{array}{l}\text { Small-size } \\
\text { company } \\
(n=258)\end{array}$} & \multirow[t]{2}{*}{$\mathrm{F}$} \\
\hline & & M & $\mathrm{SD}$ & M & $\mathrm{SD}$ & M & $\mathrm{SD}$ & \\
\hline \multirow{5}{*}{$\begin{array}{l}\text { Authentic } \\
\text { leadership }\end{array}$} & Transparency & $3.027^{b}$ & 7.720 & $3.428^{\mathrm{a}}$ & 8.890 & $3.092^{\mathrm{b}}$ & 7.723 & $9.508^{* * *}$ \\
\hline & Future orientation & $4.054^{\mathrm{a}}$ & .520 & $3.746^{\mathrm{b}}$ & .751 & $3.063^{\mathrm{c}}$ & .730 & $59.600^{* * *}$ \\
\hline & Self-awareness & $3.743^{\mathrm{a}}$ & .515 & $3.679^{\mathrm{a}}$ & .636 & $3.155^{\mathrm{b}}$ & .813 & $28.443^{* * *}$ \\
\hline & Balanced process & $2.878^{b}$ & .938 & $3.590^{\mathrm{a}}$ & .849 & $3.043^{\mathrm{b}}$ & .800 & $23.444^{* * *}$ \\
\hline & Ethicality & $3.261^{b}$ & .522 & $3.632^{\mathrm{a}}$ & .741 & $3.198^{\mathrm{b}}$ & .746 & $16.781^{* * *}$ \\
\hline \multirow{3}{*}{$\begin{array}{c}\text { Job } \\
\text { satisfaction }\end{array}$} & Wages or system satisfaction & $2.617^{\mathrm{b}}$ & .874 & $3.054^{\mathrm{a}}$ & .968 & $2.804^{\mathrm{ab}}$ & .674 & $6.589^{* *}$ \\
\hline & Job itself satisfaction & $3.707^{\mathrm{a}}$ & .749 & $3.660^{\mathrm{ab}}$ & .730 & $3.472^{b}$ & .588 & $4.996 * *$ \\
\hline & $\begin{array}{l}\text { Working condition or } \\
\text { environmental satisfaction }\end{array}$ & $3.514^{\mathrm{a}}$ & .733 & $3.450^{\mathrm{a}}$ & .778 & $3.157^{\mathrm{b}}$ & .704 & $9.452^{* * *}$ \\
\hline \multirow{3}{*}{$\begin{array}{l}\text { Organizational } \\
\text { performance }\end{array}$} & Management performance & $3.225^{\mathrm{ab}}$ & .472 & $3.489^{\mathrm{a}}$ & .806 & $3.019^{b}$ & .842 & $15.753^{* * *}$ \\
\hline & New product performance & $3.374^{\mathrm{a}}$ & .889 & $3.138^{\mathrm{ab}}$ & .930 & $2.893^{\mathrm{b}}$ & .842 & $7.049^{* *}$ \\
\hline & Job performance & 3.473 & .390 & 3.445 & .719 & 3.430 & .507 & .101 \\
\hline
\end{tabular}

${ }^{* *} p \nmid .01,{ }^{* * *} \not \chi .001, \mathrm{a}, \mathrm{b}, \mathrm{c}$ 는 scheffé 검증결과 $\left.\left.(\mathrm{a}\rangle \mathrm{b}\right\rangle \mathrm{c}\right)$.

대한 평균은 중견기업에서 가장 높았으며, 중소기 업은 $\mathrm{CEO}$ 의 진정성 리더십에 대한 인식이 가장 낮은 기업이었다.

직무만족에 있어서는 임금 및 제도 만족 $(\mathrm{F}=$ $6.589, p \times .01)$, 직무 자체 만족 $(\mathrm{F}=4.996, p<.01)$, 근무조건 및 환경 만족 $(\mathrm{F}=9.452, p<.001)$ 에서 기 업규모에 따른 차이가 나타났다. 대기업에 비해 중견기업에서 임금 및 제도 만족과 근무조건 및 환경 만족의 평균이 더 높았고, 중소기업보다는 대기업에서 직무 자체에 대한 만족이 더 높았다. 또한 임금 및 제도 만족과 근무조건 및 환경 만족 은 중견기업에서 가장 높았고, 직무 자체 만족은 대기업에서 가장 높았다. 조직성과의 경우 경영성 과 $(\mathrm{F}=15.753, \not \chi 001)$, 신상품성과 $(\mathrm{F}=7.049, p \chi .01)$ 에서 기업규모에 따른 차이를 보였고, 중소기업에 비해 중견기업에서 경영성과의 평균이 더 높았으 며, 중소기업보다는 대기업에서 신상품성과의 평 균이 더 높았다. 대기업의 경우 신상품성과가 가 장 높았고, 중견기업은 신상품성과가 가장 높았으
며, 중소기업은 경영성과와 신상품성과가 가장 낮 은 것으로 나타났다.

이상의 결과에서 $\mathrm{CEO}$ 의 진정성 리더십과 직무 만족, 조직성과가 중견기업과 대기업의 경우 비교 적 높게 나타난데 비해 중소기업은 상대적으로 낮 은 평균값을 보였다. 따라서 중소기업의 $\mathrm{CEO}$ 들은 진정한 리더의 역할에 대해 이해하고 진정성 리더 십을 통해 직원들과 소통해야 할 뿐 아니라 윤리 적 책임을 갖고 직원들의 직무만족과 조직성과를 높일 수 있는 리더십을 발휘해야 할 것이다.

\section{V. 결론 및 제언}

본 연구는 패션기업 $\mathrm{CEO}$ 의 진정성 리더십과 직무만족 및 조직성과 간의 영향관계를 알아봄으 로써 패션기업에서 직원들의 직무만족과 조직성과 를 높이는데 있어 $\mathrm{CEO}$ 가 지니고 있는 진정성 리 더십의 중요성을 확인하고, 기업규모에 따른 $\mathrm{CEO}$ 의 진정성 리더십, 직무만족 및 조직성과의 차이 
를 분석하여 인적자원관리와 경영전략에 도움이 되는 자료를 제시하고자 하였다. 본 연구의 결과 를 고려하여 결론 및 시사점을 제언하면 다음과 같다.

첫째, 패션기업 $\mathrm{CEO}$ 의 진정성 리더십은 투명 성, 미래지향성, 자아인식, 공정성, 윤리성으로 분 류되었고, 직무만족은 임금 및 제도 만족, 직무 자 체 만족, 근무조건 및 환경 만족으로 구분되었으 며, 조직성과는 경영성과, 신상품성과, 직무성과로 분류되었다. 특히 패션기업 $\mathrm{CEO}$ 의 리더십에 대해 서는 변혁적, 거래적 리더십(Hong, 2010)이나 감 성적 리더십(Kim \& Yang, 2015)에 대해서는 다 루었으나, 진정성 리더십의 구성요인을 밝힌 연구 가 부족하였으므로 본 연구의 결과는 패션분야의 리더십 연구의 확장에 기여하였다고 볼 수 있다.

둘째, 패션기업 $\mathrm{CEO}$ 의 진정성 리더십이 직원들 의 직무만족에 미치는 영향을 분석한 결과에서 투 명성과 미래지향성, 자아인식, 공정성, 윤리성은 임금 및 제도 만족에 정 $(+)$ 의 영향을 미치고 있 었고, 투명성과 미래지향성, 자아인식, 윤리성은 직무 자체 만족에 정 $(+)$ 의 영향을 미치고 있었으 며, 투명성과 미래지향성, 자아인식은 근무조건 및 환경 만족에 정 $(+)$ 의 영향을 미치는 것으로 나타 났다. 임금 및 제도 만족에는 투명성이, 직무 자체 만족에는 자아인식이, 근무조건 및 환경 만족에는 미래지향성이 가장 크게 영향을 주는 요인이었으 며, 직무만족에 있어서는 투명하고 공정하게 일을 처리하거나 행동하는 $\mathrm{CEO}$ 의 리더십과 자기 자신 에 대한 인식과 장기적인 성장 및 비전을 중시하 는 $\mathrm{CEO}$ 의 역할이 중요한 것으로 밝혀졌다. 따라 서 패션기업에서 직원들의 직무만족을 높이기 위 해서는 내부 인트라넷을 통해 $\mathrm{CEO}$ 들이 직원들과 공개적으로 정보를 공유하거나 의견을 수용하고, 직원들과의 소통을 통해 유대감을 강화할 뿐 아니 라 기업의 철학을 명확하게 하여 지속적으로 성장 할 수 있는 기업의 방향성을 제시해야 할 것이다.

셋째, 패션기업 직원의 직무만족이 조직성과에
미치는 영향을 분석한 결과, 임금 및 제도 만족, 근무조건 및 환경 만족이 경영성과에 정 $(+)$ 의 영 향을 미치고 있었고, 임금 및 제도 만족, 직무 자 체 만족, 근무조건 및 환경 만족은 신상품성과와 직무성과에 정 $(+)$ 의 영향을 미치고 있었다. 경영 성과에는 임금 및 제도 만족이, 신상품성과에는 근무조건 및 환경 만족이, 직무성과에는 직무 자 체 만족이 가장 크게 영향을 미치고 있었으며, 조 직성과를 높이는데 있어서는 개인의 업무만이 아 니라 급여체계나 승진제도, 정당한 대우와 권한 부여, 근무조건 및 환경, 동료나 상사와의 관계 등 에 대한 만족을 높일 필요성이 제기되었다. 그러 므로 패션기업에서는 개개인의 특성을 고려한 업 무배치와 함께 정당한 대우와 권한을 부여하고, 공정한 승진기회와 적절한 임금 정책 및 고용보장 을 통해 직원들의 만족도를 높인다면 기업의 성과 가 높아질 수 있을 것이다. 또한 패션산업의 특성 상 부서간의 긴밀한 업무협조가 요구되기 때문에 동료들과의 우호적인 관계 속에서 즐겁게 일할 수 있는 조직문화를 조성하고 청결하면서도 친환경적 인 근무환경을 제공해야 할 것으로 사료된다.

넷째, 패션기업 $\mathrm{CEO}$ 의 진정성 리더십이 조직성 과에 미치는 영향을 분석한 결과에서 투명성과 미 래지향성, 자아인식, 공정성, 윤리성은 경영성과에 정 $(+)$ 의 영향을 미치고 있었고, 투명성과 미래지 향성은 신상품성과에 정 $(+)$ 의 영향을 미치고 있 었으며, 자아인식, 공정성, 윤리성은 직무성과에 정 $(+)$ 의 영향을 미치고 있었다. 경영성과와 신상 품성과에는 미래지향성이, 직무성과에는 자아인식 이 가장 크게 영향을 주는 요인이었으며, 결과적 으로 조직성과에 있어서는 지속적인 성장과 목표 및 비전을 중시하거나 스스로를 인식하고 이해하 는 $\mathrm{CEO}$ 의 리더십이 중요한 것으로 나타났다. 따 라서 패션기업의 $\mathrm{CEO}$ 들은 단기적인 이익을 추구 하기보다는 장기적인 관점에서 목표와 비전을 제 시하고, 진정성 있으면서도 진솔한 감정 표현과 명확한 의사전달로 직원들과 우호적인 관계를 형 
성함으로써 조직의 성과를 높이는데 기여해야 할 것이다. 이와 함께 트렌드를 중시하는 패션산업의 비즈니스 환경을 고려하여 스피드한 기업경영 및 관리를 위해 조직 구조를 개선하거나 업무에서의 문제점 혹은 불만 사항, 의견 등을 제시할 수 있 는 인적자원 관리시스템을 구축한다면 조직의 성 과를 지속적으로 높일 수 있을 것이다.

다섯째, 패션기업의 규모에 따른 차이분석에서 는 $\mathrm{CEO}$ 의 진정성 리더십과 직무만족, 경영성과 및 신상품성과에서 차이가 나타났다. 자산규모 10 조원 이상의 대기업의 경우 $\mathrm{CEO}$ 의 미래지향성, 자아인식, 직무 자체 만족, 근무조건 및 환경 만 족, 신상품성과가 가장 높았으나, 중견기업에 비해 $\mathrm{CEO}$ 의 공정성과 윤리성이 낮았으므로 직원들의 다양한 의견에 귀를 기울이기 위한 $\mathrm{CEO}$ 의 노력 과 윤리적 책임의식을 강조하는 문화풍토의 조성 이 요구된다. 또한 상시 근로자 1,000 명 이상, 자 기자본 1,000 억원 이상, 3 년 평균 매출 1,500 억원 이상인 중견기업에서는 $\mathrm{CEO}$ 의 투명성, 공정성, 윤리성, 임금 및 제도 만족, 경영성과가 가장 높았 으나, 중소기업의 경우 $\mathrm{CEO}$ 의 진정성 리더십과 직무만족, 경영성과 및 신상품성과 등이 가장 낮 은 기업으로 밝혀졌으므로 중소기업의 $\mathrm{CEO}$ 들은 혁신적인 조직개선을 통하여 직원들과의 의사소통 을 강화하고 공정하게 일을 처리할 뿐 아니라 윤리 적 책임의식과 장기적인 목표나 비전을 중시하는 진정성 있는 리더십을 발휘하여 직원들의 직무만족 과 조직성과를 높일 수 있도록 해야 할 것이다.

결론적으로 본 연구에서는 패션기업 직원들의 직무만족과 조직성과를 높일 수 있는 진정성 리더 십의 요소들을 분석함으로써 패션기업 $\mathrm{CEO}$ 들이 리더로서 지녀야 할 리더십과 기업의 전략적 방향 성을 제시한 것에 의의가 있다. 이를 통해 패션 기업의 장기적인 성장에 있어 $\mathrm{CEO}$ 의 진정성 리 더십의 중요성을 강조하고, 진정성 리더십을 통해 직원들의 직무만족과 조직성과를 높일 수 있는 방 안을 제시하였다. 그러나 직무만족과 조직성과의
영향요인을 $\mathrm{CEO}$ 의 진정성 리더십으로 설정한 한 계가 있으므로 후속연구에서는 창조적 리더십이나 윤리적 리더십 등에 대한 연구도 필요하며, 리더 십과 조직문화를 함께 연구하는 것도 패션기업의 장기적인 성장에 도움이 될 것이다. 또한 진정성 리더십의 경우 패션분야에서 측정도구가 개발되지 않아 조직이나 인사 및 경영분야의 연구를 참고하 여 문항을 구성하였다는 한계를 갖고 있기 때문에 질적 연구와 양적 연구의 혼합형 연구방법을 통해 패션기업의 특성을 고려한 $\mathrm{CEO}$ 의 진정성 리더십 에 대한 측정도구의 개발이 요구되며, 서울 수도 권 지역 외에 다른 지역의 패션기업 직원들을 대 상으로 한 연구와 패션기업의 형태 및 특성을 고 려한 후속 연구가 이루어져야 할 것이다.

\section{References}

Agote, L., Aramburu, N., \& Lines, R. (2016). Authentic leadership perception, trust in the leader, and followers' emotions in organizational change processes. The Journal of Applied Behavioral Science, 52(1), 35-63. doi:10.1177/0021886315617531

Ambrose, S. Huston. T. \& Norman. M. (2005). A qualitative method for assessing faculty satisfaction. Research in Higher Education, 46(7), 803-830. doi:10.1007/s11162-004-6226-6

Antoncic, J. A. \& Antoncic, B. (2011). Employee satisfaction, intrapreneurship and firm growth: a model. Industrial Management \& Data Systems, 111(4), 589-607. doi:10.1108/02635571111133560

Avolio, B. J. \& Gardner, W. L. (2005). Authentic leadership development: Getting to the root of positive forms of leadership. The leadership quarterly, 16(3), 315-338. doi:10.1016/j.leaqua.2005.03.001

Avolio, B. J. Gardner, W. L. Walumbwa, F, O, Luthans, F., \& May, D. R. (2004). Unlocking the mask: A look at the process by which authentic leaders impact follower attitudes and behaviors. The leadership quarterly, 15(6), 801-823. http:// dx.doi.org/10.1016/ileaqua.2004.09.003

Avolio, B. J., Luthans, F., \& Walumbwa, F. O. (2004). Authentic leadership: Theory building for veritable sustained performance. Lincoln: The Gallup Leadership Institute.

Belias, D. \& Koustelios, A. (2014). Organizational culture and job satisfaction: A review. International Review of Management and Marketing, 4(2), 132-149. 
Brewer, G. A. \& Selden, S. C. (2000). Why elephants gallop: Assessing and predicting organizational performance in federal agencies. Journal of public administration research and theory, 10(4), 685-712.

Cha, E. A., Jung, H. W., \& Kim, Y. J. (2015). The impact of justice perceptions and authentic leadership in performance appraisal on the appraisal reactions and organizational commitment. Journal of Human Resource Management Research, 22(3), 223-245. doi:10.14396/jhrmr. 2015.22.3.223

Choi, J. E., Lee, K. M., \& Hwang, S. J. (2014). The effects of service education and empowerment for sales person of fashion companies on customer orientation, job performance and job satisfaction. The Research Journal of the Costume Culture, 22(1), 28-41. doi:10.7741/rjcc.2014.22.1.028

Choi, K. A. (2010). Effects of internal marketing factors of fashion retailers on salesperson's job satisfaction, customer orientations, and job performance (Unpublished doctoral dissertation). Dongduk Women's University, Seoul, Korea.

Choi, S. I. \& Lee, E. J. (2009). The effect of leadership of team leaders and trust of team members on job commitment and satisfaction in Fashion companies. Fashion \& Textile Research Journal, 11(3), 399408.

Clapp-Smith, R., Vogelgesang, G. R., \& Avey, J. B. (2009). Authentic leadership and positive psychological capital the mediating role of trust at the group level of analysis. Journal of Leadership \& Organizational Studies, 15(3), 227-240. doi:10.1177/ 1548051808326596

Darvish, H. \& Rezaei, F. (2011). The impact of authentic leadership on job satisfaction and team commitment. Management \& Marketing, 6(3), 421436.

Doughty, J., May, B., Butell, S., \& Tong, V. (2002). Work environment: A profile of the social climate of nursing faculty in an academic setting. Nursing Education Perspectives, 23(4), 191-196.

Gardner, W. L., Avolio, B. J., \& Walumbwa, F. O. (2005). Authentic leadership theory and practice: Origins, effects and development. San Diego, CA: Elsevier.

George, B., Sims, P., McLean, A. N., \& Mayer, D. (2007). Discovering your authentic leadership. Harvard business review, 85(2), 129-138.

Grant, A. M., Christianson, M. K., \& Price, R. H. (2007). Happiness, health, or relationships? Managerial practices and employee well-being tradeoffs. The Academy of Management Perspectives, 21(3). 51-63. doi:10.5465/AMP.2007.26421238

Harter, S. (2002). Authenticity. In C. R. Snyder \& S. J. Lopez (Eds.). Handbook of positive psychology (pp. 382-394). New York, U.S.: Oxford University
Press, xviii, 829 pp.

Herzberg, F. (1974). Motivation-hygiene profiles: Pinpointing what ails the organization. Organizational Dynamics, 3(2), 18-29. doi:10.1016/ 0090-2616(74) 90007-2

Hong, B. S. (2010). Transactions : the influence of CEO leadership on employee trust, job satisfaction, and commitment in fashion Companies. Journal of the Korean Society of Clothing and Textiles, 34(1), 102-111. doi:10.5850/JKSCT.2010.34.1.102

Hong, W. S. (2012). Effects of firms' innovative activities on their performances (Unpublished doctoral dissertation). Sogang University, Seoul, Korea.

Ilies, R., Morgeson, F. P., \& Nahrgang, J. D. (2005). Authentic leadership and eudaemonic well-being: Understanding leader - follower outcomes. The Leadership Quarterly, 16(3), 373-394. doi:10.1016/j.1 eaqua. 2005.03.002

Jang, B. J., Kim, K. Y., \& Choi, S. J. (2016). A study on the structural relationships among leader ethical leadership, job satisfaction, organizational commitment \& job performance of hotel employee. $R e^{-}$ search of Northeast asia Tourism, 12(3), 145-166.

Kernis, M. H. (2003). Toward a conceptualization of optimal self-esteem. Psychological inquiry, 14(1), 126. doi.org/10.1207/S15327965PLI1401_01

Kim, H. K. (2012). A study on the effects of leadership and organizational culture on the organizational effectiveness in the small and medium sized business (Unpublished doctoral dissertation). Tong-Myong University, Busan, Korea.

Kim, I. K. (2002). Effects of communication between fashion merchandisers and fashion designers, on job satisfaction and performance of designers (Unpublished master's thesis), Konkuk University, Seoul, Korea.

Kim, I. S. (2015). A study on the effects of social contribution activities of company members on corporate performance and sustainability (Unpublished doctoral dissertation). Konkuk University, Seoul, Korea.

Kim, J. B. (2015). A study on the influence of authentic leadership in the age of convergence on the organizational effectiveness: Revolved around effect of tuned from confidence of superior. Journal of Digital Convergence, 13(12), 125-134. doi:10.14400/ JDC.2015.13.12.125

Kim, J. S., Moon, J. S., \& Park, K. H. (2013). The impact of iob embeddedness on organizational citizenship behavior: moderating effect of authentic leadership. Journal of Human Resource Management Research, 20(5), 63-84. doi:10.14396/jhrmr. 2013.20.5.63

Kim, K. S. (2015). A Study on the effects of types of organizational culture on job satisfaction and turn- 
over intention at deluxe hotels. Tourism Research, 40(2), 131-154

Kim, S. G. \& Hong, N. S. (2015). The influence of transformational and authentic leaderships on organizational performance of a small or medium business. Korea Journal of Business Administration, 28(9), 2325-2349

Kim, S. H. \& Yang, D. W. (2015). Empirical study on the influence of emotional leadership on business performance in the fashion industry: Focused on the moderating effects of organizational culture. The Research Journal of the Costume Culture, 23(6), 1004-1020. doi:10.7741/rjcc.2015.23.6.1004

Kim, S. H., Kim, S. M., \& Park, S. J. (2008). The effect of job characteristics and person-job fit on job satisfaction, organizational commitment and turnover intention for the R\&D personnel. Yonse Business Review, 45(1), 95-122.

Kim, T. S. (2014). Effect of person-environment (job, organization) fit on job satisfaction and customer orientation : mainly on KTX train attendants. $\mathrm{Aca}^{-}$ demy of customer satisfaction management, 16(3), $87-104$.

Koo, D. W. \& Lee, S. M. (2014). The effect of general manager's authentic leadership in hotel on employee's job satisfaction, commitment, and job performance. Korea Academic Society of Hotel Administration, 23(5), 197-219.

Lee, E. J. (2009). Study on performance of result-based personnel evaluation system (Unpublished doctoral dissertation). Sungkyunkwan University, Seoul, Korea.

Lee, H. S., Yoo, Y. J., \& Kim, I. J. (2014). The moderating effect on the relationship between emotional labor and emotional exhaustion and job satisfaction. Journal of the Aviation Management Society of Korea, 12(2), 89-104.

Lee, J. H. \& Cha, J. I. (2015). Effects of authentic leadership on subordinates" job performance and turnover intention: Subordinates' organizational identification as a mediating role. The Journal of the Korea Contents Association, 15(12), 421-435. doi:10.5392/JKCA. 2015.15.12.421

Leroy, H., Anseel, F., Gardner, W. L., \& Sels, L. (2015). Authentic leadership, authentic followership, basic need satisfaction, and work role performance: A cross-level study. Journal of Management, 41 (6), 1677-1697. doi:10.1177/0149206312457822

May, D. R., Chan, A. Y., Hodges, T. D., \& Avolio, B. J. (2003). Developing the moral component of authentic leadership. Organizational Dynamics, 32(3), 247-260.

Netemeyer, R. G., \& Maxham, J. G. (2007). Employee versus supervisor ratings of performance in the retail customer service sector: Differences in predictive validity for customer outcomes. Journal of
Retailing, 83(1), 131-145. doi:10.1016/j.jretai.2006.10. 009

Oczkowski, E. \& Farrell, M. A. (1998). Discriminating between measurement scales using non-nested tests and two-stage least squares estimators: the case of market orientation. International Journal of Research in Marketing, 15(4), 349-366. doi:10. 1016/S0167-8116(98)00007-X

Park, J. H. (2016). Organizational justice and job satisfaction among faculty: The moderating effect of birthplace. Korean Journal of Public Administration, 54(2), 319-345

Park, S. Y. \& Lee, S. K. (2012). A study on the Influence of the organizational justice of the employees and the characteristics of executives on the job satisfaction and the organizational commitment. Journal of the Korean Data Analysis Society, 14(5), 2673-2687.

Park, Y. K. \& Kwon, M. K. (2010). An empirical test for employee attitudes-job performance and the exploration of a moderator. Korean Journal of Economics and Management, 28(4), 97-118,

Peus, C., Wesche, J. S., Streicher, B., Braun, S., \& Frey, D. (2012). Authentic leadership: An empirical test of its antecedents, consequences, and mediating mechanisms. Journal of business ethics, 107(3), 331-348. doi:10.1007/s10551-011-1042-3

Porter, L. W., Lawler III, E. E., \& Hackman, J. R. (1987). Behavior in Organization, New York, U.S.: McGraw-Hill.

Price, J. L. (2004). The development of causal model of voluntary turnover, in innovative theory. In R. W. Griffeth \& P. W. Hom (Eds.). Innovative theory and empirical research on employee turnover (pp. 3-32). London, England: Information Age Publishing Co.

Rego, A., Sousa, F., Marques, C., \& Cunha, M. P. (2012). Authentic leadership promoting employees' psychological capital and creativity. Journal of business research, 65(3), 429-437. doi:10.1016/j.jbusres. 2011.10.003

Ryu, D. U. \& Shin. J. K. (2013). The effects of transformational leadership on the subordinates job satisfaction and job performance with the moderating effects of subordinates personal characteristics. Journal of Human Resource Management Research, 20(2), 215-238.

Ryu, J. E. (2016). The impact of authentic leadership on the organizational commitment and innovative behavior: Focused on the organizational trust and positive psychological capital (Unpublished doctoral dissertation). Kyungsung University, Busan, Korea.

Seo, J. R. (2015). The relationship among authentic leadership, leader trust, job satisfaction of sports center CEO. The Korean Society of Sports Science, 
24(3), 717-729.

Shin, J. S. \& Soh, H. O. (2015). The effects of fashion companies' organizational types on job satisfaction and organization commitment of fashion designer. Journal of the Korean Fashion \& Costume Design Association, 17(3), 115-133.

Tett, R. P. \& Meyer, J. P. (1993). Job satisfaction, organizational commitment, turnover intention, and turnover: path analyses based on meta analytic findings. Personnel Psychology, 46(2), 259-293. doi: 10.1111/j.1744-6570.1993.tb00874.x

Walumbwa, F. O., Avolio, B. J., Gardner, W. L. Wernsing, T. S., \& Peterson, S. J. (2008). Authentic leadership: Development and validation of a theory-based measure. Journal of management, 34(1), 89-126. doi: 10.1177/0149206307308913

Walumbwa, F. O., Wang, P., Wang, H., Schaubroeck, J., \& Avolio, B. J. (2010). Psychological processes linking authentic leadership to follower behaviours. Leadership Quarterly, 21(5), 901-914.

Wong, C. A., \& Laschinger, H. K. (2012). Authentic leadership, performance, and job satisfaction: The mediating role of empowerment. Journal of Advanced Nursing, 69(4), 947-959. doi: 10.1111/j.13652648.2012. 06089.x

Yammarino, F. J., Dionne, S. D., Schriesheim, C. A., \& Dansereau, F. (2008). Authentic leadership and positive organizational behavior: A meso, multi-level perspective. The Leadership Quarterly, 19 (6), 693-707. doi:10.1016/j.leaqua.2008.09.004

Yang, P. S. \& Choi, S. B.(2012). The relationship among psychological capital, self-leadership and job satisfaction: the mediating effect of self-leadership. Journal of Organization and Management, 36(1), $1-29$.

Yoon, H. Y. (2015). Factors affecting job satisfaction among police officers (Unpublished doctoral dissertation). Hansei University, Gunpo-si, Korea. 